\title{
EL COOPERATIVISMO AGRARIO ESPAÑOL DEL PRIMER TERCIO DEL SIGLO XX *
}

\author{
SAMUEL GARRIDO HERRERO \\ Universidad Jaume I de Castellón
}

\section{RESUMEN}

Hacia 1900 comienza a configurarse en el campo español un movimiento cooperativo integrado por pequeños y medianos agricultores. Al tiempo que se evalúa la importancia de la actividad económica que generó, en el artículo se analizan algunos de los obstáculos que impidieron que adquiriera mayor desarrollo. Se llega a la conclusión de que, pese a haber aparecido algunos núcleos de gran vitalidad cooperativa, el cooperativismo agrario español se caracterizó durante el primer tercio del siglo $\mathrm{xx}$ por su descapitalización y por su escasa capacidad para consolidarse. Como resultado, su efectividad como vía de acceso del pequeño explotador a una mejora técnica fue muy limitada.

\section{ABSTRACT}

Towards the year 1900, the Spanish countryside witnessed the emergence of an agricultural co-operative movement, formed by farmers of small or middle sized holdings. The importance of the economic activity thus generated is evaluated, whilst analysing some of the obstacles which prevented its development. The conclusion reached is, that despite the existence of some co-operative nuclei of great vitality, the Spanish agricultural co-operative movement during the first third of the 20th century, was characterised by decapitalisation and by a lack of consolidation. As a result, its capacity to introduce small scale farming was very limited.

* Este trabajo, que debe mucho a las sugerencias de Jesús Millán, es una reelaboración del capitulo primero de mi tesis doctoral, Garrido (1993). Puede encontrarse allí más información una crítica más exhaustiva de las fuentes y, sobre todo, la argumentación desarrollada de afirmaciones que puedan parecer aqui un tanto aventuradas. 


\section{INTRODUCCIÓN}

En el contexto de cambios y transformaciones que provoca la crisis finisecular, hacia 1880 comienza a cobrar forma en diversas agriculturas europeas un movimiento cooperativo que durante las tres décadas siguientes se extenderá, con desigual dinamismo e intensidad, por la práctica totalidad de los países del continente. Es sabido que la Ley de Sindicatos Agricolas de 1906 actuó como detonante para la expansión de aquel fenómeno asociativo en España. En este artículo se pretende realizar una evaluación - provisional, por lo que inmediatamente se dirá- de la importancia económica que adquirió en el campo español el cooperativismo acogido a aquella disposición legal ${ }^{1}$.

La manera idónea de conseguirlo sería poner en relación su actividad con la del conjunto del sector agrario. Pero las estadísticas conocidas apenas recogen datos sobre la compra en común de factores productivos, la comercialización de las cosechas de los socios o el estado de las secciones de crédito. Y la poca información que proporcionan presenta tan grandes problemas de credibilidad que la hacen casi por completo inaprovechable. Queda el recurso de utilizar la evolución del número de sindicatos agrícolas y el de sus socios como indicador aproximado de la evolución de su peso económico. Pero ¿cuántos sindicatos agrícolas se fundaron?, ¿cuántos de ellos funcionaban?, ¿cuántos socios reunian? De manera un tanto sorprendente, porque es un tema presente en muchas reflexiones, aún no se dispone de una respuesta mínimamente precisa para preguntas tan elementales como éstas. Aparentemente, es una laguna fácil de cubrir, porque es una información que si queda consignada en numerosas estadisticas confeccionadas por la Dirección General de Agricultura (DGA) ${ }^{2}$. Pero incluso estos datos son de dudosa fiabilidad. En realidad, la Administración no tuvo nunca una idea precisa de cuántos sindicatos funcionaban ${ }^{3}$.

1 Fue el de mayores repercusiones sociales, económicas y políticas, pero no el único cooperativismo rural existente. Pervivian formas tradicionales de cooperación: los Pósitos, Carasa (1991); pero también sociedades de seguro del ganado, formas de intercambio de trabajo personal entre vecinos, etc. Sociedades campesinas de resistencia acogidas a la Ley de Asociaciones de 1887 podían desarrollar una actividad cooperativa similar a la de los «sindicatos agrícolas», Mayayo (1989), Durán (1977). Al igual que las Comunidades de Labradores o las Cámaras Agrícolas, Planas (1992).

2 Dirección General de Agricultura (1917, 1918 y 1934), Muñiz (1923, 1924 y 1927). Afirmando que se publicaban anualmente, aparece un resumen de ellas en los Anuario(s) Estadístico(s) de España.

3 Redonet (1924), p. 14; Mayayo (1989), p. 215. 
En cada gobierno civil existía un registro de los sindicatos agrícolas de la provincia. Pero en ellos no solía eliminarse a las entidades disueltas ${ }^{4}$. Las estadísticas de la DGA se hacían a partir de unos cuestionarios enviados a las cooperativas que en algún momento habían legalizado su existencia, muchos de los cuales quedaban sin respuesta. Por lo que parece, las cooperativas que no contestaban también figuraban en la estadística, y cada edición contenía una mezcla de información actualizada y otra, la mayoritaria, proveniente de las estadísticas anteriores. De las estadísticas de 1915 y 1917 si que se eliminó sindicatos desaparecidos. Aun así, los compiladores sospechaban que al menos el $40 \%$ de los citados en esta última no mantenían un funcionamiento real, y el grado de fiabilidad de posteriores recopilaciones se deterioró progresivamente, porque hasta la edición de 1934 no se volvió a depurar la información.

Por otro lado, el proceso administrativo desarrollado para aplicar la ley de 1906 suponía la existencia de dos registros centrales:

1) Registro del Ministerio de Fomento. Han resultado infructuosos los intentos de localizarlo, si bien conocemos cuántos expedientes ingresaron entre 1908 y 1914 5. Dado que las cooperativas solian iniciar con celeridad los trámites necesarios para acogerse a la ley de 1906, estos datos serán utilizados como indicador del ritmo de las fundaciones. Como se concedían exenciones fiscales, en la práctica el reconocimiento de una cooperativa como «sindicato agricola» dependía del Ministerio de Hacienda, y, tras emitir su dictamen, Fomento enviaba allí los expedientes.

2) Registro del Ministerio de Hacienda. Se ha encontrado para el período 1908-19. Ya que Fomento solía despachar con relativa rapidez la documentación, la fecha de ingreso de los expedientes en Hacienda puede dar una idea de la evolución de las fundaciones entre 1915-19 6.

Ambos registros eran acumulativos: no se hacia constar si las sociedades se disolvían y no sirven para saber las que funcionaban. En las antes menciona-

4 Instituto de Reformas Sociales (1917), «Advertencia».

5 Aparece un resumen en El Social (21-I-1915), p. 2.

6 Archivo del Ministerio de Hacienda, libro 16.714; Archivo Histórico Nacional, Hacienda, libros 4.507.9 y 7.605, y leg. 6.614. Ante la imposibilidad de efectuar una depuración de datos para el conjunto estatal, he sumado los ingresos que figuran en los libros, pero algunos sindicatos pudieron haber iniciado más de un expediente. La relativa rapidez con que fallaba Fomento tiene una excepción conocida: durante 1910-12 llegó a tener retenidos centenares de expedientes, en ocasiones más de uno o dos años. 
das estadísticas de la DGA aparecen los sindicatos existentes, con los problemas de credibilidad indicados. Queda así abierta la posibilidad de cruzar las fuentes (cuadro 1) para conseguir una visión que abarque todos los aspectos: ritmo de fundaciones, ritmo de desapariciones y sindicatos verdaderamente existentes.

\section{CUADRO 1}

Evolución del sindicalismo agrícola en España

\begin{tabular}{|c|c|c|c|c|c|c|c|c|}
\hline & (1) & (2) & (3) & (4) & (5) & (6) & (7) & $(8)$ \\
\hline 1907 & & & & & 433 & & 104 & \\
\hline$\ldots \ldots \ldots \ldots$ & 972 & 972 & 739 & 739 & 954 & & & \\
\hline 1909 & 287 & 1.259 & 366 & 1.105 & & & & \\
\hline 1910 & 190 & 1.449 & 85 & 1.190 & 1.559 & & & \\
\hline $1911 \ldots \ldots \ldots \ldots$ & 166 & 1.615 & 172 & 1.362 & & & & \\
\hline $1912 \ldots \ldots \ldots \ldots$ & 175 & 1.790 & 271 & 1.633 & & & & \\
\hline 1913 & 175 & 1.965 & 108 & 1.741 & & & & \\
\hline$\ldots \ldots \ldots \ldots$ & $102^{*}$ & 2.067 * & 210 & 1.951 & & & & \\
\hline$\ldots \ldots \ldots \ldots$ & & & 206 & 2.157 & 1.530 & & 517 & \\
\hline 1916 & & & 408 & 2.565 & 1.754 & 142.506 & 496 & 42.279 \\
\hline $1917 \ldots \ldots \ldots \ldots$ & & & 376 & 2.941 & & & & \\
\hline $1918 \ldots \ldots \ldots \ldots$ & & & 318 & 3.259 & 2.005 & 210.580 & 503 & 51.502 \\
\hline 1919 & & & 1.057 & 4.316 & 3.470 & 302.285 & 514 & 55.804 \\
\hline 1922 & & & & & 4.892 & 344.915 & 514 & 55.804 \\
\hline $1923 \ldots \ldots \ldots \ldots$ & & & & & 5.180 & 393.453 & 499 & 57.965 \\
\hline $1924 \ldots \ldots \ldots \ldots$ & & & & & 5.442 & 424.607 & 499 & 57.965 \\
\hline ............ & & & & & 5.821 & 442.206 & 501 & 57.965 \\
\hline$\ldots \ldots \ldots \ldots \ldots$ & & & & & 6.813 & 452.159 & 501 & 57.965 \\
\hline 1933 & & & & & 4.266 & 555.609 & & \\
\hline
\end{tabular}

(1) Expedientes de sindicatos agricolas ingresados en el Ministerio de Fomento. (2) Id.; ingresos acumulados. (3) Expedientes de sindicatos agricolas ingresados en el Ministerio de Hacienda. (4) Id.; ingresos acumulados. (5) Sindicatos agricolas existentes. (6) Socios de los sindicatos agrícolas. (7) Cajas rurales existentes. (8) Socios de las cajas rurales.

* Hasta junio.

Fuentes: Para las cols. (1) y (2): El Social (21-1-1915), p. 2. Para las cols. (3) y (4): Archivo Ministerio Hacienda, lib. 16.714; Archivo Histórico Nacional, Hacienda, libs. 4.507-9 y 7.605, y leg. 6.614 g. Para las cols. (5), (6), (7) y (8): Muñiz (1923), p. 12, para 1907; Cooperación (1915), I, p. 19, para 1908; Garrabou y Pujol (1988), p. 115, para 1910; Anuario Estadístico, 1916, p. 239, para 1915; Dirección General de Agricultura (1917), pp. 14-5, para 1916; Dirección General de Agricultura (1918), pp. 334-5, para 1918; Anuario Estadístico, 1919, p. 351, para 1919; Anuario Estadístico, 1921-22, p. 310, para 1922; Muñiz (1923), p. 377, para 1923; Muñiz (1924), p. 377, para 1924; Muñiz (1927) para 1926; Anuario Estadístico, 1928, pp. 516-7, para 1928; Dirección General de Agricultura (1934), p. 393, para 1933. 


\section{EL ARRANQUE DEL COOPERATIVISMO RURAL (1906-9)}

F. Rivas calculaba que los «sindicatos agrícolas» españoles eran menos de 70 a finales de $1905^{7}$. Si el cooperativismo puede considerarse como una de las respuestas de los agricultores a la creciente integración de la agricultura en el mercado y a las repercusiones de la crisis finisecular, fue en España una respuesta bastante tardia desde un punto de vista comparativo. Los 648 sindicatos agrícolas existentes en 1890 en Francia pasaban a ser 2.069 en 1900 y 6.647 en 1914. En Bélgica habían aparecido hacia 1890; en 1897, un año antes de la promulgación de la ley destinada a regularlos, había 572, que ascendían a 962 en 1904. En 1904 estaban censadas en Italia 1.092 cajas rurales católicas. La estadística alemana informaba de la existencia de 17.162 cooperativas agrarias de todo tipo en 1905 . En Dinamarca se creó en 1882 la primera cooperativa de producción de manteca, y en 1900 ya había 1.0298 . En cualquier caso, gracias a una Ley de Sindicatos Agrícolas que concedía exenciones fiscales y otros «beneficios» a los agricultores asociados, la Administración española actuó de incitadora para reducir las distancias existentes en esta parcela en tre el campo español y otras agriculturas europeas. $Y$ los resultados, en apariencia al menos, fueron espectaculares.

Se afirma que en 1907 ya había 433 sindicatos agrícolas ${ }^{9}$. En 1908 (primer año de aplicación de la ley de 1906) entraban en Fomento 972 expedientes, y según la DGA a finales de año funcionaban 954 sindicatos, que pasaban a ser 1.559 en 1910 (cuadro 1). O sea, que en 1908 se habrían hecho más de 500 fundaciones, y otras tantas durante 1909-10. En gran medida, porque, en su deseo de «ganar el campo al socialismo», los católicos se habian lanzado a crear sindicatos a un ritmo casi frenético. Pero muchos de los que aparecieron como resultado de sus campañas de propaganda eran fundaciones apresuradas, más o menos ficticias, nacidas con escasas perspectivas de no fracasar. El jesuita Antonio Vicent, el principal animador del primer sindicalismo católico-agrario, re-

7 Rivas (1926), p. 214.

8 Para Francia, Cleary (1989), p. 35. Para Bélgica, Le Soc (1909), p. 16. Para Italia, Sapell (1981), p. 37. Para Alemania, Elías (1910), p. 22. Para Dinamarca, Gascón (1926). Pero en ninguna de las obras citadas se informa del grado de fiabilidad de las estadisticas, que es posible que no fuera siempre muy distinto del español. Por ejemplo, en 1927 estaban censadas en Francia 2.728 cajas rurales Durand, pero sólo actuaban unas dos mil, Gueslin (1984), p. 262. En el departamento de Var muchos sindicatos no funcionaban, Reinaudo (1980).

9 Muñiz (1923), p. 12. También habria 104 cajas rurales, pero es especialmente complicado seguir la evolución de éstas. Según Rivas (1923), pp. 8-9, que da unas cifras que discrepan sensiblemente de las recogidas en el cuadro 1 , en 1905 funcionaban 73 cajas rurales (con 12.714 socios), 439 en 1910 (60.318 socios), 591 en 1915 (78.450 socios) y 648 en 1920 (83.316 socios) Pero inmediatamente después se contradice: en 1920 serian 725 , el $90 \%$ unidas a un sindicato. 
clutó en ocasiones los socios para sus fundaciones, sin haberlos avisado previamente, repansando en compañía del párroco el censo de población ${ }^{10}$. Y solía pasar que aquellas cooperativas, nacidas sin haberse asegurado una minima fidelidad por parte de los socios (que las abandonaban en el mismo instante de surgir alguna dificultad), se disolvian poco después o mantenian una existencia meramente nominal.

De todas maneras, es innegable que aquella propuesta asociativa tuvo un gran atractivo para amplios sectores del campesinado español. En parte, porque nacía avalada por el sacerdote del lugar. Sobre todo, porque lo que los «propagandistas» ofrecian - para «evitar los actuales males de emigración y socialismo en el campo"- era el "mejoramiento de la producción agrícola" "11. Pero era una declaración de intenciones que chocó frecuentemente con la modestia de los resultados obtenidos.

La actividad cooperativa apenas tuvo incidencia en la esfera de la comercialización. En el País Valenciano aparecieron pocas cooperativas citrícolas ${ }^{12}$, y en las regiones ganaderas no se constituyeron lecherías cooperativas - se afirma que la primera se creó en $1913^{13}$. Parece que tampoco se difundieron las secciones de comercialización en las áreas trigueras. En Castilla o en Aragón muchos sindicatos disponian de «paneras sindicales», pero durante este período inicial no aparecen fábricas de harina: los socios seguían comercializando en solitario y el sindicato, cuando disponía de la capacidad financiera necesaria, les hacía préstamos en la época de la recolección, con la cosecha como garantía, para ayudarlos a resistir frente a los acaparadores. $Y$ a excepción de la comarca de la Conca de Barberà y de algunos casos aislados, tanto en Cataluña como en el País Valenciano hay que esperar a mediados de la década de 1910 para que se produzca una cierta difusión de las bodegas cooperativas ${ }^{14}$.

Por lo que se refiere a la práctica del crédito, muchas de las primeras cooperativas, tan faltas de recursos como sus socios, sólo pudieron conceder sumas minúsculas ${ }^{15}$. En los casos conocidos, la media de los préstamos suele situarse alrededor de las 100 o 200 pesetas por prestatario. Un dinero que podía servir para superar alguna dificultad concreta, para adquirir algunas viñas americanas, unos cuantos quintales de abono o semilla para la nueva cosecha.

\footnotetext{
10 Vicent (1906), pp. 66 y 32-3.

11 Revista Católica de Cuestiones Sociales (abril 1912), p. 262.

12 Abad (1991).

13 Cooperación (1915), II, p. 20.

14 Mayayo (1989), Pujol (1984), Piqueras (1981).

15 Andrés (1984), p. 123.
} 
Pero que, por su modestia, difícilmente podría ayudar a introducir de manera continuada y progresiva inputs de capital en las pequeñas explotaciones campesinas. Como excepción, suele citarse la importante actividad crediticia de las cajas rurales de Navarra, y, especialmente, la de las cajas de Badajoz que formaban parte de la Federación Agraria Extremeña. Pero estas últimas, también como excepción, estaban «constituidas por propietarios ricos», mientras que en la vecina provincia de Cáceres, como en general en toda España, las integraban «modestos labradores» 16 .

La mayoría de sindicatos se habrían dedicado a la compra-venta de abonos y de artículos de consumo. Partiendo de un consumo anterior muy bajo, excepto en la agricultura mediterránea más dinámica, la utilización de abonos químicos experimentó un significativo incremento entre 1897 y $1912{ }^{17}$. Durante estos años, en la periferia mediterránea o en el Valle del Ebro (Pais Valenciano, Cataluña, Navarra o La Rioja) las adquisiciones de fertilizantes de algunos sindicatos o federaciones fueron de gran envergadura ${ }^{18}$. Pero en las áreas interiores eran compras de poco volumen. Los sindicatos católicos de la provincia de Salamanca adquirieron en 1908 unas $327 \mathrm{t}$ de abonos, superfosfatos en su inmensa mayoría. La federación de Ciudad Rodrigo compró en 1910 más de mil cien toneladas, pero bajaron durante los años inmediatamente posteriores a una media de $900 \mathrm{t}$, repartidas entre unas 20 cooperativas. El Sindicato Central de Aragón —formado en 1913 por 98 entidades - vendió 1.480 t de abonos en 1910, 1.680 en 1911, 1.981 en 1912 y 2.750 en $1913^{19}$. Ejemplos similares podrian multiplicarse, pero las cantidades pocas veces dejarían de ser modestas. Si en la agricultura interior el consumo de fertilizantes químicos se extendió más allá de la gran explotación, parece indudable que gran parte del mérito lo tendrían los sindicatos. Pero los conocimientos que actualmente tenemos sobre aquellas entidades no permiten suponer que los pequeños labradores socios pudieran hacer, en general, un uso relativamente abundante de abonos. Lo que no obsta para que su actividad tuviera un alto valor cualitativo: «Hace pocos años no eran conocidas de los labradores las excelencias de los abonos químicos. Hoy se hacen ya compras no sólo para un pueblo, sino

16 Cooperación (1915), I, pp. 21-4

17 Gallego (1986).

18 Segun Yoldi (1916), p. 524, hacia 1912 se consumian anualmente en Navarra 27.330 t de abonos químicos, mientras que la Cooperativa Central de las Cajas Rurales Católicas vendía por aquellos momentos 11.060 t. En el Pais Valenciano, los socios del sindicato de Castellón consumian unas $700 \mathrm{t}$ de abonos hacia 1910, y casi el doble los socios del de Burriana, Garrido (1993).

19 Para el conjunto de Salamanca, La Paz Social (1908), pp. 388 y ss. Para Ciudad Rodrigo La Paz Social (1910), pp. 659 y ss.; y Cooperación (1915), II, p. 21. Sobre Aragón, El Obrero Agricola (sept. 1913), pp. 797-9. 
para diócesis o regiones» 20 . Gracias a los sindicatos, algunos pueblos de la diócesis de Ciudad Rodrigo habrian conseguido «duplicar y hasta triplicar sus cosechas» 21.

A niveles aún modestos, entre 1898 y 1912 también se produjo en España una expansión en el uso de maquinaria agrícola ${ }^{22}$. Parece razonable suponer que las cooperativas, adquiriendo máquinas que después alquilaban a los socios, habrían actuado como centros de difusión de estas nuevas tecnologías. Pero todo parece indicar que lo conseguido durante esta etapa inicial fue más bien escaso. En 1909 se calculaba que disponían de maquinaria entre el 15 y el $20 \%$ de los sindicatos confesionales ${ }^{23}$. Para 1910 se hablaba de la existencia de 96 asociaciones agrícolas católicas en la diócesis de Zaragoza, seis de las cuales eran cajas rurales y 90 sindicatos agrícolas. De éstos, todos tenian sección de crédito, «aunque sólo fuese para préstamos de abonos químicos y de simiente», pero únicamente 8 disponian de maquinaria agrícola ${ }^{24}$. Junto a algún caso local aislado - como puede ser el sindicato de Yelo (Soria) - Navarra seria una de las principales excepciones ${ }^{25}$. Menos conocida, es posible que fuera similar la contribución de los sindicatos agrícolas de La Rioja, cuya federación compró en 1913 «tres seleccionadoras, un bravant, tres gradas, una bomba, una máquina de injertar, un triturador» ${ }^{26}$. También sobre Castilla la Vieja y León es posible encontrar información esporádica sobre adquisiciones de maquinaria. En 1910 la federación de Ciudad Rodrigo repartió entre cinco sindicatos cuatro arados Rud-Sach, dos del Sindicato Nacional de Maquinaria y otro Brabant. Pero puede que tuviera más importancia la contribución a la mejora del instrumental tradicional, porque a título individual aquellos sindicatos hacían pedidos de hierro "para calzar y enfricar las rejas de los arados» ${ }^{27}$. Sin que sepamos los resultados, en Cáceres se pretendió impulsar en 1908 un «sindicato comunal» para adquirir trilladoras ${ }^{28}$. En las memorias de

20 Boletín del Consejo Nacional de las Corporaciones Católico-Obreras (1908), p. 261.

21 Anuario Social de España. Año I: 1915-16 (1916), p. 110.

22 Gallego (1986).

23 Jiménez (1909), p. 179.

24 Noguer (1912), p. 519. La habían adquirido por medio del Sindicato Central de Aragón, que hasta 1913 se limitó a comprar seleccionadoras. Antes de 1910 había comprado una. En 1910 sirvió 7, sistema "Marot», y 5 en 1911. En 1912 las 779.000 pesetas invertidas en abonos contrastan con las 5.000 pesetas dedicadas a «maquinaria agricola, semillas y otros artículos». No se indica que durante el primer semestre de 1913 se comprara ninguna máquina. El Obrero Agrícola (sept. 1913), pp. 797-9.

25 Abundante información en Yoldi (1916). La referencia a Yelo, en Cooperación (1915), II, p. 24.

26 El Obrero Agricola (mayo 1914), p. 147.

27 Robledo (1984), p. 145. Las compras de los arados modernos, en Andrés (1984), p. 275.

28 Sánchez (1979), p. 124. 
las federaciones del País Valenciano no aparecen nunca alusiones a compras de maquinaria, aunque muchos sindicatos valencianos contaban con ciertas máquinas - prensas, agramadoras de cáñamo, trilladoras de arroz, desgranadoras de maiz- o con una «sección de herramientas». Quizá estas adquisiciones no se canalizaran a través de las federaciones y se deba a ello la dificultad de encontrar información.

\section{UNA INTERRUPCIÓN DEL CRECIMIENTO (1910-15)}

Pero aquella labor no siempre tuvo continuidad. Promulgada inmediatamente después de las revueltas castellanas y andaluzas de 1904-5, desde finales de 1909 hasta al menos 1915 la Ley de Sindicatos Agrícolas casi dejó de tener vigencia práctica ${ }^{29}$. En parte como resultado de ello, hacia 1909-10 el movimiento cooperativo experimentaba una fuerte crisis. Disminuyó sensiblemente el número de fundaciones y se disolvieron muchas de las primeras cooperativas. Según la DGA, en 1915 existían 1.530 sindicatos, cuando cinco años antes se habia hablado de la existencia de 1.559 (cuadro 1). Como entre enero de 1911 y junio de 1914 habían ingresado en Fomento 614 expedientes, en 1915 ya habría desaparecido, como minimo, el $30 \%$ de los sindicatos agricolas fundados antes de ese año.

Las secuelas de la crisis finisecular propiciaron que desde ciertos sectores de las clases propietarias, por motivos sociales y políticos, se considerara prioritario el objetivo de mantener las pequeñas explotaciones. A pesar del proteccionismo, ello parecía imposible sin un aumento de la productividad campesina, que pasaba por una mejora técnica difícilmente alcanzable por el pequeño explotador, por su pobreza, de manera aislada ${ }^{30}$. Muy sensible a estas preocupaciones, el Estado tenía interés para que el pequeño productor rural no quedase marginado de la política dinamizadora que estaba desplegando. De hecho, muchas de las iniciativas estatales (y básicamente la legislación sobre cooperativismo) iban dirigidas a él, desde el momento que comenzó a pensarse que el proceso de dinamización agrícola tendría que apoyarse en gran medida en la explotación familiar, por la gran capacidad de resistencia a desaparecer que estaba presentando ${ }^{31}$. Desde los últimos años del siglo XIX la Iglesia venía repitiendo que la solución a la «cuestión agraria» era la cooperación interclasista animada desde la confesionalidad. Una de las confluencias entre tantas

\footnotetext{
${ }^{29}$ Garrido (1993), pp. 127-196.

${ }^{30}$ Garrabou (1990), p. 74.

31 Villares y L. Fernández (1992).
} 
miradas dirigidas al pequeño agricultor estaba en los sindicatos agrícolas. Impulsados mayoritariamente por una Iglesia que aportó un sustrato ideológico y a los sacerdotes encargados de hacer y vigilar las fundaciones, representaban un modelo de cooperación guiado por criterios de armonización social. Y podían ser controlados fácilmente por la gran propiedad.

La argumentación anterior es coherente, pero ha de fallar en algún punto, porque entre tantas facilidades resulta dificil entender por qué las cooperativas adquirieron tan escasa envergadura y por qué fracasaron con tanta facilidad. En realidad, parece que todo transcurrió de manera mucho más compleja. Según dijeron repetidamente los activistas católicos, en la práctica los pilares de la cooperación habrian quedado reducidos a dos: ellos y los propios campesinos. Porque la Administración no aplicaba correctamente la ley de 1906 y «los ricos ... nos hacen la guerra, no fiándose en nosotros» ${ }^{32}$.

Cuestionando las construcciones teóricas en las que se acepta la existencia -universal y atemporal- de un «anticooperativismo campesino» ${ }^{33}$, en muchas regiones españolas los pequeños explotadores, de tierra propia o ajena, mostraron hacia 1906 una gran receptividad a la propaganda cooperativa. Pero, aparte de su descapitalización, los obstáculos a los que tuvieron que hacer frente las primeras cooperativas fueron a menudo insuperables. Generalizar es simplificar, porque se dieron, en el espacio y en el tiempo, una gran variedad de situaciones; frecuentemente, contradictorias. Pero las obstrucciones más importantes provinieron de la gran propiedad, de manera directa o indirecta (a través del Estado). Porque los sectores de terratenientes que prestaron su apoyo a aquellos experimentos fueron una minoria frente a otros que desconfiaban del asociacionismo campesino. Aunque fuera un asociacionismo obsesivamente antisocialista, impregnado de conservadurismo y dispuesto a reservarles un asiento en todas las directivas de las federaciones o confederaciones que se creasen.

Los sindicatos agrícolas estaban formados básicamente por pequeños y medianos agricultores. Pero no necesariamente por pequeños y medianos pro-

32 Archivo Vicent, carta del obispo de Pamplona a Antonio Vicent, 17.02-1912. «No somos capaces de interesar a las gentes acomodadasm, arzobispo de Sevilla a Vicent, 18-01-1911. La «gente principal», según el obispo de Huesca, mostraba en su diócesis «desconfianza y frialdad» ante los sindicatos, 19-07-1907. Este archivo, que contiene básicamente la correspondencia recibida por el jesuita, se conserva en la Facultad de Teologia de Sant Cugat del Vallès.

${ }^{33}$ Por ejemplo, Rogers y Svenning (1973). Una crítica a estas interpretaciones esencialistas, en Contreras (1984). El anticooperativismo como resultado de la diferente estrategia empresarial de cada segmento social de agricultores, en Caballer (1982). Un intento de aplicar estas ideas al análisis histórico, en Garrido (1993). También alli, la Administración y la vía no democrática de cooperación impulsada por la Iglesia como responsables parciales del rechazo campesino a las cooperativas. 
pietarios, porque sus socios podían ser (o podían ser al mismo tiempo) arrendatarios y aparceros, que posiblemente necesitaban salir de la explotación familiar para trabajar a jornal un número importante de jornadas al año. Que a partir del interclasismo inicial pudieran degenerar en sociedades campesinas de resistencia no parece que preocupara excesivamente a las clases terratenientes. Se dieron casos, pero la misión de la Iglesia era evitarlos. Sí que podían preocuparles las repercusiones económicas de aquel fenómeno asociativo. Porque sin que ello implique un comportamiento «feudal» o irracional, en determinadas circunstancias el propietario capitalista puede optar por una estrategia maximizadora que produce la obstrucción de la mejora técnica ${ }^{34}$. Una estrategia en la que la renta - y el control de los canales de crédito- puede ocupar un lugar central. Es lo que parece que ocurrió en al menos una parte de la España interior ${ }^{35}$. Precisamente, en algunas de las zonas donde más se difundieron los sindicatos agrícolas después de 1906, por abundar la pequeña explotación y ser fuerte la influencia que la Iglesia conservaba sobre el campesinado.

La comparación con Francia puede ser esclarecedora. En amplias regiones, la sociedad rural francesa permanecía durante el último cuarto del siglo XIX sometida a la influencia de una clase de grandes propietarios de origen aristocrático. Entusiastas de las primeras formulaciones del catolicismo social, la fundación de los sindicatos agrícolas franceses partió inicialmente de estos sectores, con objeto de conservar el «ordre naturel des choses». Dentro de éste, la renta de la tierra era la que les ofrecía los medios económicos necesarios para su supervivencia, y no deja de ser significativo que los primeros sindicatos surgieran en Francia, hacia 1880, coincidiendo con el inicio de una fuerte y mantenida tendencia a la caida de la renta ${ }^{36}$. En la España interior estudiada por R. Robledo la crisis agraria finisecular no produjo la «derrota» del rentista, sino que en los inicios del siglo xx la renta experimentó, después del estancamiento o la ligera caída durante los años de la crisis, una decidida recuperación. Como ha explicado R. Robledo, el propietario castellano fomentaba la competencia para acceder a la tierra arrendable y anulaba las iniciativas que pudiesen dar cierta independencia económica al explotador campesino. Es decir, las iniciativas que pudiesen redundar en una disminución de la presión existente para coger tierra en arrendamiento. El cooperativismo actuaba en esta dirección, por lo que desde la perspectiva del rentista podía ser contemplado - y pienso que lo fue de manera bastante generalizada - como una amenaza contra la renta ${ }^{37}$.

\footnotetext{
34 Bhaduri (1987).

35 Robledo (1984).

36 Servolin (1984), pp. 24.5

37 «Esas Cajas, que tan eficazmente promueven el bienestar de las clases agrícolas, favorecen
} 
Considerando el peso político de aquellos sectores de terratenientes en la España de la Restauración, no puede resultar muy fantasioso suponer que la política cooperativa estatal partia lastrada por importantes limitaciones.

Pero también limitaciones políticas de otro orden. El apoyo que el Estado presta a la pequeña explotación es un buen indicador de la influencia del campesinado sobre el bloque de poder. En Argentina el sector cooperativo no despegó durante las primeras décadas del siglo $\mathrm{xx}$, pero gracias a las cooperativas los pequeños y medianos agricultores canadienses pudieron controlar una porción importante de la comercialización del trigo e influyeron sobre los precios de venta al intermediario. En un estudio comparativo, se llega a la conclusión de que el distinto grado de acceso al poder político es uno de los factores que explican una evolución tan distinta: como en Canadá los gobiernos dependían (en mayor medida que en Argentina al menos) de las variaciones de la opinión expresadas a través de las urnas, necesitaban el apoyo electoral de los pequenos agricultores, lo que produjo una politica agraria más favorable a sus intereses ${ }^{38}$.

A la vez, en las sociedades occidentales el cooperativismo fue una de las vias que permitieron al campesino ampliar sus derechos políticos. Se ha indicado para Francia que, gracias a él, en los inicios del siglo xx el pequeño agricultor había pasado a ser visto por la sociedad global como una masa organizada con la que el Estado necesitaba contar. Pero, previamente, el sindicalismo agricola francés había podido consolidarse porque, desde Gambetta y Méline, el Estado republicano, entrando en competencia con los notables monárquicos, se había visto en la necesidad de «gagner les ruraux» para la República como garantía para su perennidad. Desde el momento que se entendió que la población rural, aún mayoritaria, iba a convertirse progresivamente en el árbitro de la vida política ${ }^{39}$. Las batallas políticas también se ganaban en los pue-

principalmente a la modesta propiedad rural, y contribuyendo a aumentar el número de los pequeños propietarios que labran por su cuenta y a disminuir, por consiguiente, la oferta del colonato, colocarian al rentero en situación favorable para contratar en mejores condiciones...., Chaves (1975), II, p. 420. En Carrión de los Condes se «atrajo a los obreros con la idea de procurar en el futuro sindicato estudiar lo de los arrendamientos de fincas y prevenir las competencias ruinosas que se hacen estos colonos, pujando por la renta de los solares o tierras, actitud a la cual se debe atribuir en gran parte el que los colonos paguen excesivo canon de renta, con lo cual los propietarios estiman serles más útil arrendar las tierras que labrarlas por cuenta propia», carta de F. Arce a S. Nevares, 26-06-1909, en Aldea (1987), p. 6. «Con los arriendos en común», repetia en sus mitines un sacerdote extremeño, «se destruiria la competencia ruinosa. $Y$ suprimido ... el arrendatario logrero y explotador, y con éste los subarriendos, abaratarian [los sindicatos] las rentas de los terrenos laborables en beneficio de los pequeños labradores», carta de Simón Oliveros a A. Vicent, 19-07-1910 (Archivo Vicent).

38 Solberg (1987).

39 Moulin (1988), pp. 135 y ss. 
blos rurales en la España de la Restauración, pero con una diferencia fundamental respecto a la Francia de la III República: aunque con lentitud y vacilaciones, el mundo rural francés estaba entrando en la etapa de la movilización y la opinión, cosa que no pasó en España.

Uno de los objetivos de la reacción conservadora que dio lugar a la Restauración fue liquidar el notable proceso de movilización popular posterior a 1868. Durante el más de medio siglo que siguió a 1875 de los beneficiarios del régimen forjado por Cánovas no partieron nunca intentos serios de ampliar el consenso hacia las clases subalternas y de legitimar su dominio a través del juego democrático. Al contrario que el Estado republicano francés, aquí los gobernantes no se vieron en la necesidad de atraerse a la opinión del campo, y una de las bases sobre las que se hizo descansar la perpetuación del régimen fue (incluso después del sufragio universal masculino de 1890) mantener a la población rural desmovilizada políticamente, función de los poderes locales. A pesar de la importancia del control sobre la Administración, la perpetuación de las formas de poder caciquil guardaba relación con la capacidad de los propietarios de mantener mecanismos de control social de carácter personalista: a través del crédito entre particulares (a menudo a intereses usurarios), del control sobre el uso de un factor productivo esencial como es el agua, del control de los canales de comercialización o del control sobre el mercado de trabajo. El cooperativismo agrícola, que incidía sobre todos estos ámbitos, no dejaba de ser un elemento perturbador. Por ello, la acción del Estado nació en España inmersa en una contradicción. Existia una voluntad de dinamizar la actividad agrícola; para ser efectivo, se consideraba imprescindible que este proceso llegara a la pequeña explotación, y para conseguirlo era preciso fomentar el cooperativismo. Pero el cooperativismo (aunque estuviera impulsado mayoritariamente por los católicos) producía unas repercusiones políticas no deseadas. En el contexto general de la Restauración, no puede extrañar que la segunda consideración tendiera a pesar más que la primera ni que el miedo a la agitación social en el campo fuera, en último extremo, lo que hiciera oscilar la balanza hacia uno $u$ otro extremo.

Después de 1912 se reactivó la propaganda católico-agraria en CastillaLeón ${ }^{40}$, pero parece que inicialmente sólo produjo resultados importantes en la provincia de Palencia y en algunas áreas de Burgos o Valladolid. Se dice que en los inicios de la guerra europea los sindicatos de Palencia representaban, junto a los de La Rioja, las cajas rurales de Navarra y Badajoz y las cooperativas citrícolas valencianas, una excepción dentro del panorama general de

${ }^{40}$ Castillo (1979), pp. 75 y ss. 
decadencia. Estas últimas eran presentadas como la expresión más perfecta del cooperativismo español en un informe de 1915 del Instituto Internacional de Agricultura, lo que no es sino una muestra de las limitaciones del movimiento cooperativo en el campo español. Como consecuencia de la mala campaña naranjera de 1908-9, comenzaron a desarrollarse a partir de 1909 y decayeron durante los años iniciales de la primera guerra mundial. Alcanzaron su máximo esplendor durante la campaña de 1911-12, cuando entre 16 entidades exportaron unos $290.000 \mathrm{qm}$ de naranja ${ }^{41}$. O sea, el $5,3 \%$ de los cítricos españoles exportados.

\section{LA GRAN EXPANSIÓN (1916-20)}

En 1916 aumentaron los expedientes ingresados en Hacienda (408, por una media de 175 entre 1910-15) y las entidades teóricamente existentes (1.754, 224 más que en 1915). Las primeras repercusiones del conflicto europeo sirvieron para reactivar el ritmo fundacional. Especialmente, en Castilla la Vieja y León, donde, con el beneplácito de la gran propiedad, el movimiento católico-agrario comenzó a canalizar la movilización de los pequeños y medianos campesinos en demanda de una mayor protección y de unos altos «precios mínimos» de venta del trigo. Pero ello no impedía que muchas de las primeras cooperativas siguieran sucumbiendo: en 1916 se habían disuelto o habían dejado de funcionar 161 sindicatos, 44 de ellos en la provincia de Valladolid y 60 en el conjunto de las nueve provincias castellano-leonesas. De los 1.754 «existentes», 706 no habían contestado a la petición de la DGA para que enviasen datos actualizados de su actividad, cosa posiblemente debida «a que no realizan labor alguna útil y eficaz para el fomento y desarrollo de los intereses agrícolas" ${ }^{42}$.

En cualquier caso, estaba creciendo la capacidad de las cooperativas para atraer socios, y ya no únicamente pequeños explotadores. En las regiones periféricas que anteriormente hacían un uso abundante de abonos químicos, las economias que permitían las compras mancomunadas iban ganando atractivo para el conjunto de agricultores conforme subían sus precios. En el sistema cereal interior puede que influyera, más que el encarecimiento de los fertilizantes, la contracción de las disponibilidades a causa del hundimiento de las importaciones. Alli la guerra propició un contexto de acumulación de beneficios

41 Cooperación (1915), II, pp. 14-20.

42 Dirección General de Agricultura (1917), pp. 314-5 y 13. 
especulativos en las empresas agrarias. Durante 1914-18 los precios de los abonos crecieron mucho más que los de los productos agricolas, pero en un nivel de abonado de la tierra aún bajo, un incremento de éste provocaria un aumento de los rendimientos que compensaría los gastos efectuados por el alza relativa de los precios de los abonos. Por eso, el consumo «debió caer simplemente porque no se encontraban abonos en el mercado, aunque se pagara mucho» ${ }^{43}$. Las cooperativas, que pudieron importar a través de la Confederación Nacional Católico-Agraria (CNCA), se dedicaban precisamente a proporcionar abonos.

Pero fue durante el «trienio bolchevique» de 1918-20 cuando, al tiempo que la conflictividad social en el campo alcanzaba cotas máximas, el cooperativismo agrario español recibió un impulso definitivo. $\mathrm{Y}$ es también entonces cuando deja de haber dudas de que se hizo efectiva la confluencia en los sindicatos de la gran propiedad territorial, el Estado y la Iglesia. Como resultado, los 1.754 sindicatos de 1916, en su mayoría muertos, pasaban (cuadro 1) a ser 2.005 en $1918,3.471$ en $1919^{44}$ y 4.892 en $19222^{45}$.

Adquirieron alguna fuerza los intentos de exportar las cosechas de los socios. En 1918 sólo 3 de los sindicatos integrantes de la católica Federación Valenciana tenian «sección de exportación», pero pasaron a ser 42 en $1919^{46}$. Por su excepcionalidad, tiene más interés que durante la guerra europea los sindicatos católicos, «además de vender trigo en el interior a precios elevados, pudieron exportar" ${ }^{47}$. Los sindicatos católico-agrarios valencianos enviaron durante aquellos años a los mercados extranjeros naranjas, cebollas y otras producciones de huerta, pero también arroz: por medio de R.O (18-III-1920), se concedió en exclusiva a la Federación Valenciana un permiso para exportar el arroz de la provincia de Valencia. Lo que puede dar una pista más sobre por qué algunos sectores de propietarios acomodados estaban potenciando ahora el cooperativismo: sirviéndose de las facilidades concedidas por motivos sociales a los sindicatos, habrian conseguido participar de los beneficios derivados de los altos precios de los alimentos de primera necesidad en el mercado europeo y esquivar legalmente las trabas a la exportación.

43 Gallego (1986), pp. 187.9.

44 Anuario Estadístico, 1919, p. 351. En Anuario Estadístico, 1920, p. 310, se repiten las mismas cifras. Posiblemente, están infladas: durante 1919 entraron en el Ministerio de Hacienda 1.057 expedientes, pero a finales de 1919 «existían» 1.466 sindicatos más que en 1918.

45 Anuario Estadístico, 1921-22, p. 310. En Muñiz (1923 y 1924) aparece la fecha de constitución de los sindicatos «existentes». En recuento de P. Carasa, de los 5.442 sindicatos de 1924 se da la fecha de constitución de 5.159; 994 de ellos se fundaron en 1919, 1.058 en 1920, 359 en 1921 y 161 en 1922.

46 Garrido (1993), p. 64.

47 Arribas (1989), p. 45. 
Pero todo parece indicar que continuó siendo una actividad encaminada preferentemente hacia las compras en común. Disponemos de mucha información fragmentaria, pero faltan casi por completo series de datos que permitan una visión de conjunto. De éstas, las únicas mínimamente aprovechables que conozco (reproducidas en el cuadro 2) se refieren a las adquisiciones efectuadas por las federaciones integrantes (a partir de abril de 1917) de la CNCA. Su utilización resulta muy problemática ${ }^{48}$, pero el cuadro puede servir para proporcionar alguna orientación.

Sorprenden las escasas inversiones en maquinaria. Esta partida sólo aparece consignada con asiduidad en las federaciones del Alto Ebro (Navarra y La Rioja) y de Castilla la Vieja y León, pero con sumas muy modestas. En CastillaLeón se destinaron en 1920 a adquirir máquinas 151.000 pesetas, que quedan en casi nada dividiéndolas por los 1.213 sindicatos que aquellas federaciones decian representar. Aunque ya se ha dicho que es posible que algunos sindicatos, caso de hacerlas, hiciesen estas compras en solitario. Puede, en consecuencia, que la suposición de R. Garrabou de que los sindicatos actuaron eficazmente como centros difusores de la mecanización sea demasiado optimista, pero parece excesivamente contundente la conclusión en sentido contrario de P. Carasa ${ }^{49}$.

Son más significativos los datos sobre los abonos (especialmente los de 1920), porque parece que durante los años contemplados estas compras sí se canalizaban a través de las federaciones. Destacan claramente dentro de la Confederación tres núcleos por el volumen de esta actividad: País Valenciano, Alto Ebro y Castilla-León. Si bien la imagen varía sustancialmente al calcular la relación entre abonos adquiridos y sindicatos integrantes de las federaciones (cuadro 3). Pueden plantearse objeciones de peso contra la representatividad de estas medias, pero del cuadro se desprende la existencia de al menos dos modelos: mientras que en algunas de las áreas más dinámicas el sindicalismo agrícola confesional se dedicó principalmente al suministro de abonos, en la agricultura interior serían muy distintos los mecanismos de captación de socios. Si en los libros de actas de las entidades valencianas suelen aparecer alusiones a los abonos desde la reunión fundacional, en los libros de la potente Federación Católica de Villalón (Valladolid), fundada en 1919, no son citados hasta 1932 , sin que pueda deducirse de ello que antes no se compraran ${ }^{50}$. El

48 Porque los católicos utilizaban la estadistica como arma de propaganda y lo que declaraban no se ajustaba siempre a la realidad. Porque faltan datos de algunas federaciones. Y porque los sindicatos, y en especial los más potentes, podian haber comprado por su cuenta.

49 Garrabou (1990), Carasa (1990) p. 893.

50 Martinez (1982), p. 131. 


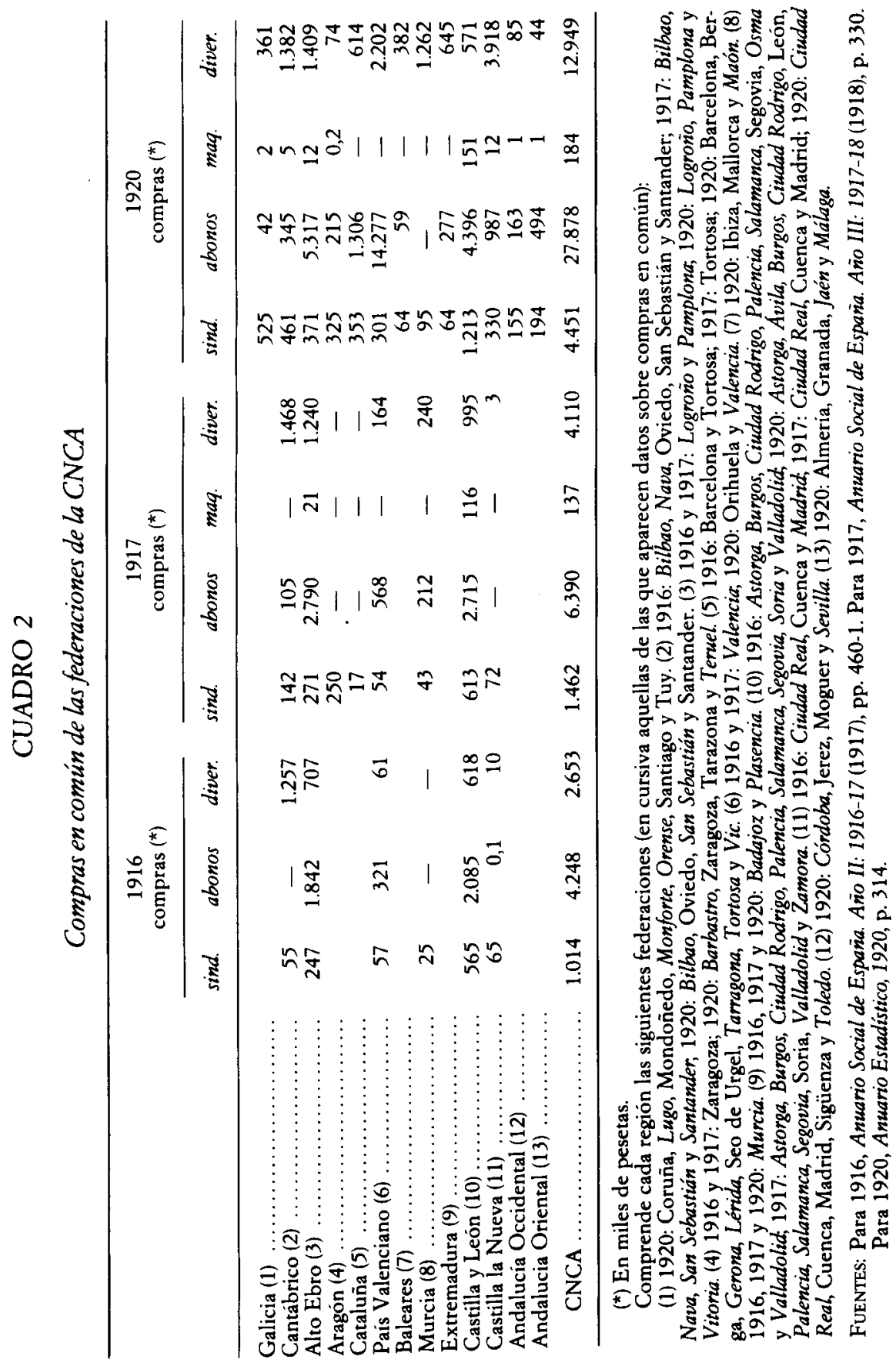


motor de los sindicatos de la Tierra de Campos parece que fue la «panera sindical» y una fábrica de harina. Pero no puede generalizarse para toda Castilla, porque las fábricas cooperativas de harina siempre fueron pocas. También el caso gallego parece muy diferente: en 1921 la federación de La Coruña vendió a sus sindicatos productos por valor de 785.000 pesetas, pero sólo 75.000 pesetas en abonos y la mayoría del resto en comestibles ${ }^{51}$.

\section{CUADRO 3}

Compras de abonos de las federaciones de la CNCA

\begin{tabular}{|c|c|c|c|}
\hline & \multicolumn{3}{|c|}{ Abonos/sindicato (en miles de ptas.) } \\
\hline & 1916 & 1918 & 1920 \\
\hline Galicia (1) $\ldots \ldots \ldots \ldots \ldots \ldots \ldots$ & & & 0,32 \\
\hline Cantábrico (2) ...... & & 1,07 & 3,48 \\
\hline 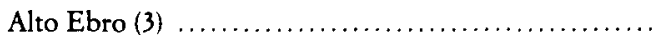 & 7,43 & 10,29 & 14,33 \\
\hline 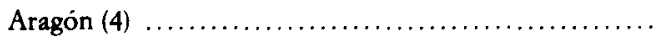 & & & 2,03 \\
\hline Cataluña (5) $\ldots \ldots \ldots \ldots \ldots \ldots \ldots \ldots \ldots \ldots \ldots \ldots \ldots \ldots \ldots \ldots$ & & & 6,16 \\
\hline Pais Valenciano $(6) \ldots \ldots \ldots \ldots \ldots \ldots \ldots \ldots \ldots \ldots \ldots \ldots \ldots \ldots \ldots \ldots$ & 5,64 & 10,53 & 55,77 \\
\hline 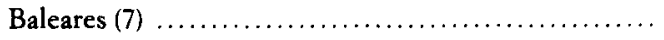 & & & 6,52 \\
\hline 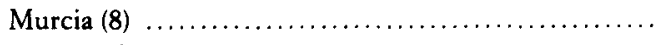 & & 4,93 & \\
\hline 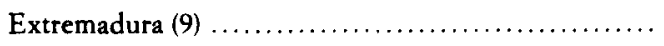 & & & 4,33 \\
\hline Castilla y León $(10) \ldots \ldots \ldots \ldots \ldots \ldots \ldots \ldots \ldots \ldots \ldots \ldots$ & 3,75 & 4,43 & 4,39 \\
\hline 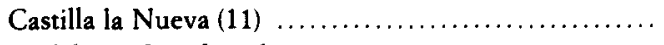 & & & 4,63 \\
\hline Andalucia Occidental (12) ......................... & & & 1,53 \\
\hline Andalucia Oriental (13) $\ldots \ldots \ldots \ldots \ldots \ldots \ldots \ldots \ldots \ldots \ldots \ldots$ & & & 5,49 \\
\hline CNCA ...... & 4,59 & 5,93 & 10,29 \\
\hline
\end{tabular}

FUENTES: Las indicadas en el cuadro 2, que también indica qué federaciones integran cada región. Se ha considerado únicamente las federaciones de las que se conoce la cantidad invertida en abonos.

También muestran los cuadros 2 y 3 que la considerable implantación de las cooperativas en las áreas interiores no es incompatible con el hecho de que la actividad desarrollada por la mayoria de ellas fuera casi siempre muy modesta en términos susceptibles de ser sometidos a una cuantificación. Para que hubiese tenido un efecto apreciable en cada localidad, y a partir de

51 Martinez (1989), p. 113 
la suma de éstas sobre la evolución del sector, habría sido necesario que los sindicatos hubiesen mantenido una actuación continuada. ¿Pudieron mantenerla?

\section{LOS AÑOS VEINTE: ¿CONSOLIDACIÓN O DESINTEGRACIÓN?}

Superados los efectos catastróficos de la guerra europea sobre la utilización de fertilizantes químicos, con la década de los veinte comienza una nueva fase, prolongada hasta 1928, de expansión de su uso, igual que del de maquinaria agricola 52 . ¿Pudo influir sobre ello la labor de unas cooperativas agrarias que ya desde 1919-20 eran tan numerosas?

Los indicadores sobre la actividad económica que éstas desarrollaron continúan siendo de similares características que en momentos precedentes: escasos, parciales y merecedores de escasa confianza. La CNCA, por ejemplo, decía estar formada en septiembre de 1926 por 54 federaciones, 3.034 sindicatos y 1.669 cajas rurales, la mayoría de las cuales eran secciones de un sindicato. Durante el año anterior habrian dedicado 22.077 .000 pesetas a comprar abonos y 400.000 a adquirir maquinaria agrícola. Poseerian 28 bodegas cooperativas, 17 fábricas de harina, 5 de conservas, 1 de sulfuro de carbono, 1 de jabón, 1 de hielo, 2 de luz, 29 molinos de aceite y 4 panaderías. Las cajas rurales tendrian en depósitos 250 millones de pesetas, y los préstamos a sus socios ascenderian a 200 millones ${ }^{53}$. Aunque es difícil de creer, se dice que la Liga Nacional de Campesinos, otra federación estatal de cooperativas confesionales fundada en 1923 por Antonio Monedero ${ }^{54}$, reunia 3.250 entidades en 1936. Implantada especialmente en las provincias de Palencia, Burgos y Segovia, y con menor intensidad en el resto de Castilla-León y en Aragón, compró $500 \mathrm{t}$ de fertilizantes químicos en $1925,1.000$ en $1926,5.000$ en $1928,10.015$ en $1930,11.000$ en 1933 y 12.000 en 1936.

Como posible explicación del porqué de un volumen de negocio aparentemente tan modesto, diversos indicios apuntan que después del auge fundacional de 1919-20 muchas cooperativas no pudieron consolidarse y desaparecieron a corto plazo. Si ello no queda reflejado en las estadísticas es porque, como ya se ha dicho, su fiabilidad experimentó durante los años veinte una to-

52 Gallego (1986).

53 Revista Social Agraria (sept. 1926), p. 10. Bases para una valoración crítica de esta información, en Castillo (1979), pp. 267 y ss. De todas maneras, las compras de abonos y maquinaria parecen referirse a las federaciones, pero muchos sindicatos no operaban ahora a través de ellas.

${ }^{54}$ Castillo (1979), pp. 481.6. 
tal degradación. Aunque en alguna ocasión se afirme lo contrario, los datos proporcionados por la Dirección General de Agricultura no estaban convenientemente actualizados: parece que se añadia a las estadísticas los sindicatos de nueva creación, pero no se eliminaban los que dejaban de funcionar ${ }^{55}$. De confirmarse esta suposición, en 1924, 1925 y 1926 se habria hecho una media de 213 fundaciones por año. O sea, 4,3 sindicatos por provincia y año. Prácticamente no se habrían creado cooperativas en Navarra o La Rioja; posiblemente, porque ya habían alcanzado una implantación notable durante los años anteriores. Pero en Castilla-León habría aparecido una media de 5,7 sindicatos por provincia y año, 10,4 en el País Valenciano, 6,7 en Galicia, 4,6 en Cataluña, 5,3 en Extremadura y 1,5 en Andalucía. Ahora bien, en algunas provincias las entidades que estaban desapareciendo serian mucho más numerosas ${ }^{56}$.

Desde 1906-8 este modelo de cooperación interclasista había encontrado su marco idóneo en las áreas peninsulares con mayor peso de la pequeña explotación y la pequeña propiedad de la tierra. Aunque en 1919-20 también se extendió por las provincias meridionales latifundistas ${ }^{57}$, durante los primeros años veinte los sindicatos andaluces, inviables como fórmula cooperativa debido a la extrema descapitalización de los socios, desaparecieron de manera masiva al dejar de recibir el apoyo de sus impulsores. Pero los espectros de aquellas entidades siguieron figurando durante toda la década de 1920 en las estadísticas de la DGA (cuadro 4). Posiblemente, la fuerte presencia de los sindicatos en Extremadura o en Castilla la Nueva durante el periodo se deba a la misma razón. Porque en 1926 la distribución geográfica de los sindicatos «es de notar que sigue, poco más o menos, la de la propiedad territorial», y sólo «en las comarcas en que los pequeños propietarios son numerosos la sindicación está muy desarrollada» ${ }^{58}$. Es decir, que durante la Dictadura de Primo

55 Aun asi, las cifras de 1928 destacan por su exageración. Provienen del Anuario Estadístico, 1928, pp. 516-7, que da una cifra total de sindicatos - 7.101 - que no se corresponde con los 6.813 que resultan al sumar los datos provinciales. Pero puede que el error tipográfico no esté en la suma final, sino en la provincia de La Coruña, que pasó de tener 300 sindicatos en 1926 a tener 51 en 1928: fue la única provincia en la que disminuyó entre 1918-28 el número de sociedades.

56 Si en 1920 se decia que la CNCA reunía 4.451 sindicatos, Anuario Estadístico, 1920, p. 314 -y en alguna ocasión se afirma que eran más de 5.000 -, en diciembre de 1923 habrian bajado a 3.212, Redonet (1924), p. 257. Según la CNCA, a mediados de 1929 eran «cuatro mil escasos» los sindicatos que «actuaban» de verdad. O sea, que no llegaban al $60 \%$ de los existentes. Pero estos cálculos merecen poco crédito, porque entre los que actuaban estaban incluidos los «más de tres mil Sindicatos» que la Confederación decía tener afiliados, Revista Social Agraria (abril 1929), p. 170. En Anuario Social de España, 1929 (1930), pp. 380-2, sólo se concede a la CNCA 2.276 sindicatos.

57 Castillo (1979).

58 Revista Social Agraria (sept. 1926), p. 11. 


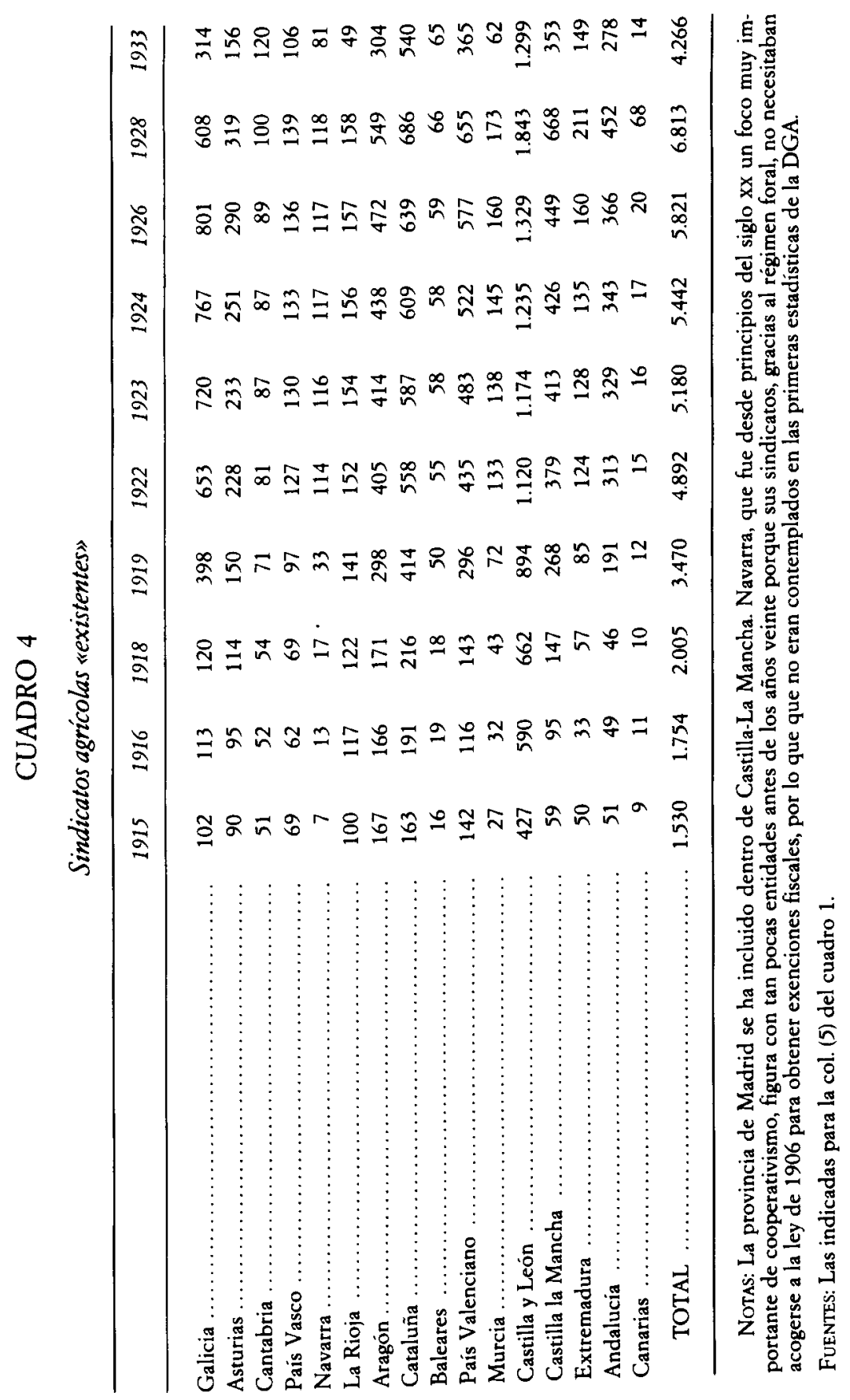


de Rivera el cooperativismo acogido a la ley de 1906 habría vuelto a replegarse en la mitad septentrional peninsular.

Aun así, el gran crecimiento del número de sindicatos agrícolas en CastillaLeón, Galicia, Aragón, Cataluña o el País Valenciano parece deberse en parte a la «inercia» estadística, porque también en estas zonas proliferaron las disoluciones. Es cierto que determinadas entidades locales y comarcales, casi siempre aquellas que incluían entre sus socios a un núcleo importante de agricultores relativamente acomodados (caso de muchos sindicatos valencianos), experimentaron durante esta década un gran desarrollo. Pero no parece que las cosas marcharan igual de bien, en general, para los mayoritarios sindicatos casi exclusivamente formados por los propietarios muy pobres de los que hablaba J. J. Castillo. Igual que había pasado después de la promulgación de la ley de 1906, todo parece indicar que durante los años veinte fueron muchos los pequeños agricultores ganados por la propaganda cooperativa. Pero todo parece también indicar que las sociedades que formaban, descapitalizadas y con pocas posibilidades de obtener recursos, fracasaban con gran facilidad. En 1924 el Ministerio de Hacienda pretendió anular la franquicia postal que se había concedido a los sindicatos agrícolas en 1906, y desde el órgano de prensa de la CNCA se aseguraba que «... su existencia económica es tan menguada y tan estrecha que no podrían el 90 por 100 de los Sindicatos existentes sostener este nuevo gasto» 59 .

Cuando en 1922 se me ordenó visitase los sindicatos federados [a la Federación Católico-Agraria de La Coruña, relataba en 1927 el inspector de ésta] se me dio una lista de 120, [y] pude comprobar que en la práctica no existían más que 46. Desde entonces se repite el fenómeno: todos los años pasan a mejor vida 10 ó 12 sindicatos, y hay que fundar más para compensar esta sangria ${ }^{60}$.

A pesar de algún sonado fracaso, en Navarra fue muy larga la vida media de las cooperativas: en 1935 perduraba el $91 \%$ de las cajas rurales y sindicatos agrícolas constituidos entre $1902-35^{61}$. La única manera de comprobar si - como parece - fue un caso excepcional, pasa por la realización de monografias regionales. Mientras tanto, el «Censo electoral social» elaborado por el Ministerio de Trabajo en 1932 puede ser utilizado para obtener alguna conclu-

59 Revista Social Agraria (abril 1924), p. 5.

60 Citado por Martinez (1989), p. 74.

61 Majuelo y Pascual (1991), pp. 458-62. 
sión provisional sobre cómo evolucionó el ritmo de fundación-desaparición de sindicatos a lo largo de la década de los veinte ${ }^{62}$.

Aunque parece que todas las entidades mencionadas en el «Censo» mantenian un funcionamiento real, no son todas las que funcionaban: no recoge las Ligas de Campesinos, y provincias con una fuerte tradición cooperativa pueden aparecer con muy pocos sindicatos: Logroño (1 sindicato), Salamanca (3), 'Segovia (0), Pontevedra (1), Orense (3) o Murcia (6). Pero el «Censo» es una muestra significativa del cooperativismo agrícola español en aquel momento. El resultado de agrupar por periodos los 1.252 sindicatos de los que se facilita el año de constitución (no se indica de otros 64) es el siguiente:

$$
\begin{array}{ccccccc}
\frac{\text { antes } 1906}{24} & \frac{1906-9}{157} & \frac{1910-3}{93} & \frac{1914-8}{304} & \frac{1919}{160} & \frac{1920}{66} & \frac{1921-4}{100} \\
\frac{1925-6}{53} & \frac{1927-9}{143} & \frac{1930-2}{152}
\end{array}
$$

Ya sabemos que en 1919 o en 1920 se habían fundado casi tantos sindicatos como durante 1906-9. También sabemos que al menos el $30 \%$ de estos últimos se disolvió antes de 1915. De los 1.316 que se conoce con seguridad que funcionaban en 1932, 157 se habian fundado en 1906-9, pero 160 en 1919 y sólo 66 en 1920. Lo que indica que las fundaciones del trienio bolchevique tuvieron una vida media aún más corta que las cooperativas pioneras. En Castilla-León continuaba existiendo en 1932 un número considerable de las entidades constituidas durante la primera guerra mundial. Ahora bien, Burgos era, con 84 , la provincia castellano-leonesa que más sindicatos tenía en el «Censo». Setenta y dos de ellos habían sido fundados en 1919 o antes, lo que no deja de contrastar fuertemente con los 248 expedientes de sindicatos burgaleses que habian ingresado en el Ministerio de Hacienda durante 1908-19, incluso aceptando que muchos de los que todavía existían en 1932 puedan no aparecer. De aquellos 72 sindicatos, 50 habían sido fundados entre 1914-18, pero los expedientes que entraron en Hacienda durante el mismo período fueron 147. O sea, que las fundaciones no se detuvieron durante los años veinte, pero las desapariciones habrían sido abundantísimas. Extremo que una nueva recopilación de la DGA, de mejor calidad que las anteriores, viene a confirmar.

Si para enero de 1927 se indicaba la existencia de 1.329 sindicatos en Castilla-León - 1.843 en diciembre de 1928-, en diciembre de 1933 seguirían

62 Gaceta del 14 y 19 agosto y 21 enero de 1932. 
existiendo $1.299{ }^{63}$. Pero al menos el $40 \%$ de ellos habían sido reconocidos por el Ministerio de Hacienda a partir de $1930^{64}$. Además, entre estos 1.299 sindicatos castellanos figuran 506 entidades federadas a la Liga Nacional de Campesinos, que no habían aparecido en el «Censo electoral» de 1932 y que quizá no habían contemplado tampoco las anteriores estadísticas de la DGA. De una provincia de fuerte tradición cooperativa, Valencia, se dice que habia 353 sindicatos en 1926 ( 373 en 1928); en 1933 sólo eran 157, la cuarta parte de los cuales reconocidos después de 193065 .

Es decir, que en la estadística editada en 1934 ya se han depurado las entidades disueltas presentes en las ediciones anteriores, aunque no sabemos si fue un expurgo completo. Como resultado, en diciembre de 1933 había 1.555 sindicatos menos que el 1 de enero de 1927: 4.266 en lugar de 5.821, con una disminución del $26,7 \% 66$. Si, desde el supuesto que el «Censo electoral» de 1932 ofrece una muestra significativa, puede calcularse que aproximadamente un $23 \%$ de los sindicatos existentes en 1933 habían sido fundados después de 1926, viene eso a significar que en 1934 se habría eliminado alrededor de la mitad de los sindicatos que en 1927 se consideraba «existentes». (Y el porcentaje sería mucho mayor en el caso de que en la estadística de 1927 no figurasen las Ligas de Campesinos, lo que habrá de ser comprobado.) Mientras tanto, los socios habían pasado de 442.206 en enero de 1927 a 555.609 en diciembre de 1933. "Consecuencia de todo ello es que muchas entidades de escasa importancia han desaparecido, a la vez que otras de las antiguas han adquirido mayor desenvolvimiento y han surgido nuevas con gran vitalidad ...) 67 .

${ }^{63}$ Respectivamente, Muñiz (1927), Anuario Estadístico, 1928, pp. 516-7, y Dirección General de Agricultura (1934).

64 Arribas (1989), p. 40.

65 Entre 1909-19 el Ministerio de Hacienda habia fallado favorablemente sobre 283 expedientes de sindicatos de la provincia de Valencia, pero en 1933 sölo pervivian 81. En 1917 y 1919 el número de reconocimientos fue especialmente elevado: 87 y 71; pero en 1933 sólo quedaban, respectivamente, 14 y 19 de ellos. Se ha podido detectar que algunas entidades reconocidas antes de 1919 efectuaron después alguna modificación de estatutos y volvieron a pasar por el Ministerio de Hacienda, apareciendo en la estadística la fecha del segundo reconocimiento. Pero puede quedar compensado por las «refundaciones»: los sindicatos de que consta una fecha de aprobación anterior a 1919 y que, después de haber dejado de funcionar durante años, habian vuelto a realizar actividad cooperativa.

66 Disminución aproximada, porque en Dirección General de Agricultura (1934), pp. 354-91, aparece una relación, que no se ha considerado, de sindicatos que enviaron tarde los datos. También se ha de decir que Castillo (1979), p. 286, informa que durante la Segunda República (pero parece que a partir de 1934) desde la CNCA se propugnó una variante táctica consistente en la potenciación de las entidades comarcales: es posible que sindicatos católicos diminutos se hayan agrupado y puedan continuar existiendo a pesar de no aparecer en la estadistica.

67 Dirección General de Agricultura (1934), «Introducción» sin paginar. 
CUADRO 5

El sindicalismo agrícola español en 1933

\begin{tabular}{|c|c|c|c|c|c|c|}
\hline & sindicatos & socios & $\begin{array}{c}\text { Capital } \\
\left(10^{3} \mathrm{pts}\right)\end{array}$ & $\begin{array}{l}\text { Socios/ } \\
\text { sindicato }\end{array}$ & $\begin{array}{c}\text { Ptas./ } \\
\text { sindicato }\end{array}$ & $\begin{array}{l}\text { Ptas./ } \\
\text { socio }\end{array}$ \\
\hline Burgos $\ldots \ldots \ldots \ldots \ldots$ & 241 & 13.934 & 610 & 58 & 2.532 & 44 \\
\hline Palencia $\ldots \ldots \ldots \ldots \ldots$ & 146 & 11.541 & 1.306 & 79 & 8.946 & 113 \\
\hline Soria $\ldots . . . . . . . \ldots \ldots . .$. & 51 & 2.872 & 188 & 56 & 3.688 & 65 \\
\hline Valladolid ............. & 77 & 7.370 & 1.046 & 96 & 13.584 & 142 \\
\hline Zamora .... & 109 & 7.490 & 511 & 69 & 4.690 & 68 \\
\hline Alicante $\ldots \ldots \ldots \ldots \ldots$ & 79 & 15.083 & 3.782 & 191 & 47.874 & 251 \\
\hline Castellón (1) ............ & 129 & 28.969 & 3.140 & 224 & 24.343 & 108 \\
\hline Valencia $\ldots . . . . . . . .$. & 157 & 53.558 & 7.030 & 341 & 44.779 & 131 \\
\hline Castilla y León (2) ...... & 621 & 43.207 & 3.661 & 69 & 5.896 & 85 \\
\hline País Valenciano ......... & 365 & 97.610 & 13.952 & 267 & 38.226 & 143 \\
\hline España (3) & 3.292 & 514.461 & 65.757 & 156 & 19.975 & 128 \\
\hline
\end{tabular}

(1) Se ha considerado que los 8.254 .005 ptas. de capital del sindicato de Almazora serían en realidad 254.005 ptas., que es una cifra similar a la que declaran los otros sindicatos potentes de la Plana de Castellón.

(2) No se ha considerado las provincias de León (cuyos 445 sindicatos, con un total de 13.814 socios, únicamente reunirian 269.000 ptas.), Salamanca ( 92 sindicatos, 4.358 socios y 38.000 ptas.), Segovia ( 59 sindicatos, 4.488 socios y 75.000 ptas.) ni Ávila, pero ésta porque a sus 79 sindicatos, con 4.733 socios, se les otorga un capital de casi 4 millones de ptas.

(3) Además de las cuatro provincias castellano-leonesas ya citadas, no se ha considerado, por parecer el capital reunido excesivamente abultado o demasiado reducido, las provincias de Madrid, Orense, Oviedo, Santa Cruz de Tenerife y Tarragona.

FueNTE: Dirección General de Agricultura (1934).

Pero era una vitalidad que no puede generalizarse. En diciembre de 1933 , más de un cuarto de siglo después de la promulgación de la ley de 1906, los 4.266 sindicatos agrícolas españoles sólo reunían en conjunto un capital efectivo de 99 millones de pesetas. Es decir, una media de 23.000 pesetas por sindicato y de 178 pesetas por socio. Estas cifras sirven como indicador elocuente del bajo nivel de actividad que pudo desarrollarse. Pero son también una ad. vertencia de la desconfianza con que ha de ser contemplada la fuente de donde provienen, a pesar de ser la más exacta de todas las estadísticas de la DGA Los sindicatos de la provincia de Tarragona (148, con 21.672 socios) reunían un capital de más de 17 millones de pesetas. Cosa poco creible si se considera que la provincia que la sigue por este concepto, Valencia (157 sindicatos y 
53.558 socios), únicamente reunía 7 millones. Se han reelaborado los datos eliminando los que parecían más difícilmente aceptables (cuadro 5): el capital por sindicato y por socio que resulta es aún mucho más bajo. Se ha considerado las provincias castellano-leonesas y las valencianas para mostrar que las medias esconden enormes diferencias regionales y provinciales. Pero también pueden ser muy acusadas las diferencias comarcales, y hay entidades que pueden distorsionar las medias debido a su excepcional envergadura. Por ejemplo, el $40 \% \mathrm{del}$ capital de los 129 sindicatos de la provincia de Castellón pertenecía a sólo 5 sindicatos de la Plana, que era la comarca que acogia al $43 \%$ de los sindicatos agricolas castellonenses y acaparaba el $57 \%$ del capital sindical provincial.

De manera similar a la Plana, en algunas zonas de la mitad septentrional peninsular ya estaba fuertemente consolidado en el inicio de los años treinta un cooperativismo muy activo. Por lo que se sabe, en la Tierra de Campos, en el área de actuación del «sindicato regional» de Carrión de los Condes, en muchas comarcas valencianas y catalanas, en gran parte de Navarra... A manera de islotes más o menos dispersos, también funcionaban en muchos pueblos entidades locales potentes y dinámicas. Pero parecen haber sido la excepción en un mundo rural español en el que las cooperativas tenían poca vitalidad y, sobre todo, mostraron muy escasa capacidad para consolidarse. Hasta el punto de que a lo largo del primer tercio del siglo $\mathrm{xx}$ parecen haber aumentado las distancias respecto a los países que ya disponian a finales del siglo XIX de un tejido asociativo rural más desarrollado. En 1914 más de las tres cuartas partes de los agricultores franceses permanecían fuera del movimiento cooperativo y sindical, pero durante el período de entreguerras la proporción de no sindicados disminuyó a la mitad 68 .

\section{CONCLUSIONES}

Aunque es innegable que desde la Iglesia, la Administración y ciertos sectores de propietarios partieron en los inicios del siglo XX poderosos estímulos a favor de la organización cooperativa del pequeño agricultor, las cooperativas tuvieron que hacer frente a múltiples obstrucciones e intentos de desestabilizarlas.

Desde el Estado se creó un marco legislativo muy favorable, con disposiciones que pueden ser consideradas adecuadas desde un punto de vista técnico. Pero no se aplicaban o se aplicaban con muchas reticencias. Es cierto que

68 Moulin (1988), pp. 138 y 185. 
fueron determinados sectores de propietarios los que animaron aquel fenómeno asociativo. Pero el cooperativismo tendia a facilitar el funcionamiento económico del campo en condiciones favorables para el pequeño explotador, y fue bastante frecuente que los propietarios lo contemplaran con cierta desconfianza, o incluso que se opusieran frontalmente a él. De manera aún más frecuente, no se oponían, pero tampoco colaboraban, por entender que ser socios de una cooperativa comportaba unos inconvenientes que no quedaban compensados por las ventajas que podían obtener ${ }^{69}$.

La incitación a organizarse fue recogida por muchos pequeños y medianos agricultores. Pero a la hora de la verdad solía pasar que las cooperativas quedaban abandonadas a sus propias y únicas fuerzas. Por eso, se ha concluido en otro lugar 70 que la capacidad del cooperativismo para consolidarse dependió en gran medida de la capacidad económica de los sectores campesinos implicados. En este sentido, no parece que las condiciones fueran excesivamente favorables en la que suele convencionalmente llamarse España interior. Es posible que la visión un tanto escorada hacia el pesimismo que aquí se ha ofrecido esté condicionada por la precariedad de las fuentes. También es posible que cuando se hagan monografías locales similares a la que M. Martínez dedicó a la Tierra de Campos se muestre que en muchas otras zonas castellano-leonesas o aragonesas existieron núcleos cooperativos que tal vez no generaban cifras de negocio espectaculares, pero que tuvieron continuidad y pudieron prestar una ayuda importante para el funcionamiento de las pequeñas explotaciones campesinas. Pero mientras no se disponga de mayor información lo que se sabe no invita a un mayor optimismo.

Las alusiones al cooperativismo se utilizan en la historiografía agraria española para dar fuerza a muy diversas argumentaciones: una muestra de la efectividad de los nuevos rumbos de la política agraria estatal después de la crisis finisecular, una ayuda decisiva para el acceso de muchos desposeídos a la propiedad, instrumento de modernización de la agricultura... No se ha pretendido en este artículo negarlo. Al menos en el regadío valenciano, las cooperativas desempeñaron con éxito tales papeles, aunque tampoco estuviera su camino exento de dificultades. Lo que se ha pretendido es advertir sobre los peligros que entraña utilizar como comodín explicativo algo que debería ser previamente explicado. Que es tanto como reclamar la urgente aparición de nuevos estudios que permitan ampliar lo poco que hoy se conoce sobre el cooperativismo agrario español del primer tercio del siglo $\mathrm{xX}$.

${ }^{69}$ Caballer (1982).

70 Garrido (1993). 


\section{BIBLIOGRAFIA}

ABAD, Vicente (1991): Cooperativas citricolas de exportación (1892-1990), Valencia, ANECOOP

ALDEA, Quintín y otros, eds. (1987): Iglesia y sociedad en la España del siglo XX, II, Madrid, CSIC.

ANDrEs, José (1984): Pensamiento y acción social de la Iglesia en España, Madrid, EspasaCalpe.

Anuario Social de España. Año I: 1915-16 (1916), Barcelona, Acción Social Popular.

Anuario Social de España. Año II: 1916-17 (1917), Barcelona, Acción Popular.

Anuario Social de España. Año III: 1917-18 (1918), Barcelona, Acción Popular.

Anuario Social de España, 1929 (1930), Madrid, Fomento Social.

ARribas, José M. (1989): «El sindicalismo agrario: un instrumento de modernización de la agriculturan, Historia Social, 4, pp. 33-52.

BHADURI, Amit (1987): La estructura económica de la agricultura atrasada, México, FCE.

CABALLER, Vicente (1982): «El comportamiento empresarial del agricultor en la dinámica de formación y desarrollo de cooperativas agrarias», Agricultura y Sociedad, 23, pp. 193-216.

Carasa, Pedro (1990): «Sindicalismo católico agrario y control social», en Actas del II Congreso de Historia de Palencia, III, 2, Palencia, Diputación, pp. 877-908.

(1991): «El crédito agrario en España durante la Restauración», en B. Yun (coord.): Estudios sobre capitalismo agrario, crédito e industria en Castilla, Junta de Castilla y León, pp. 289-343.

Castillo, J. J. (1979): Propietarios muy pobres, Madrid, Ministerio de Agricultura.

Cleary, M. C. (1989): Peasants, politicians and producers, Cambridge University Press.

CONTRERAS, Jesús (1984): «La teoría de la 'modernización' y su concepto de cultura campesina: reflexiones críticas», en E. Sevilla (coord.): Sobre agricultores y campesinos, Madrid, Ministerio de Agricultura, pp. 109-148.

COOPERACION (1915): «La cooperación en la agricultura española», en Boletín mensual de Instituciones Económicas y Sociales, Roma, marzo (I, pp. 11-27) y abril (II, pp. 14-25).

Chaves, Luis (1975): informe para Oligarquía y caciquismo, Madrid, Ed. de la Revista de Trabajo, II, pp. 415-422.

Direccion General de Agricultura (1917): Memoria descriptivo-estadística de las entidades agrícolas y pecuarias en $1 .^{\circ}$ de enero de 1917 , Madrid.

- (1918): Memoria social agraria... en $1 .^{\circ}$ de abril de 1918, Madrid.

- (1934): Censo estadístico de Sindicatos Agricolas y Comunidades de Labradores, Madrid.

Duran, J. A. (1977): Agrarismo y movilización campesina en el país gallego, Madrid, Siglo XXI.

EliAS, José (1910): El crédito agrícola y las cajas rurales, Barcelona, Imp. Barcelonesa.

GALLEGO, Domingo (1986): «Transformaciones técnicas de la agricultura española en el primer tercio del siglo xx», en R. Garrabou y otros (eds.): Historia agraria de la España contemporánea, III, Barcelona, Crítica, pp. 171-229.

GaRRABOU, Ramon (1990): «Sobre el atraso de la mecanización agraria en España (1850-1933)», Agricultura y Sociedad, 57, pp. 41-77.

Garrabou, Ramon, y Pujol, Josep (1988): «La especialización de la agricultura mediterránea y la crisis. Cataluña y el Pais Valenciano", en R. Garrabou (ed.): La crisis agraria de fines del siglo XIX, Barcelona, Crítica, pp. 94-130. 
GARRIDO, Samuel (1993): El sindicalisme catolico-agrari al País Valencià. Cooperativisme confessional, millora tècnica $i$ mobilització camperola a Espanya després de la crisi agrària finisecular, tesis doctoral, Universidad de Valencia.

GASCON, Antonio (1926): Dinamarca agrícola y cooperativa, Madrid.

GUESLIN, André (1984): Histoire des crédits agricoles, París, Economica.

InStTUTO DE REFORMas Sociales (1917): Estadistica de asociaciones, Madrid.

JiménEZ, Inocencio (1909): «Los sindicatos agrícolas católicos», La Paz Social, 26, pp. 169-180.

LE SOC (1909): Vademécum del propagandista de sindicatos agrícolas, Zaragoza, Biblioteca de La Paz Social, 3." ed.

Majuelo, Emilio, y PASCuAl, Ángel (1991): Del catolicismo agrario al cooperativismo empresarial, Madrid, Ministerio de Agricultura.

MARTINEZ, Alberte (1989): O cooperativismo católico no proceso de modernización da agricultura galega, Pontevedra, Diputación.

Martinez, Mateo (1982): Tierra de Campos, Valladolid, Inst. Cultural Simancas.

Moulin, Annie (1988): Les paysans dans la societé française, París, Seuil.

MAYAYO, Andreu (1989): «El cooperativisme agrari: un moviment dualm, en C. Mir (ed.): Actituds polítiques $i$ control social a la Catalunya de la Restauració, Lleida, Estudi General, pp. 209-232.

MuÑIz, Lorenzo (1923): La acción social agraria en España y memoria estadística de las entidades agrícolas y pecuarias en $1 .^{\circ}$ de abril de 1923, Madrid, Ministerio de Fomento.

- (1924): La acción social agraria y memoria estadística.. en $1 .^{\circ}$ de diciembre de 1924, Madrid, Ministerio de Fomento.

- (1927): La acción social agraria y memoria estadística... en $1 .^{\circ}$ de enero de 1927, Madrid, Ministerio de Fomento.

Noguer, Narciso (1912): Las cajas rurales en España y en el extranjero, Madrid, Razón y Fe.

Piqueras, Juan (1981): La vid y el vino en el País Valenciano, Valencia, Alfons el Magnànim.

Planas, Jordi (1992): «L'associacionisme agrari català al primer terç del segle XX», $R e-$ cerques, 25 , pp. 139-157.

Pujol, Josep (1984): «Les crisis de malvenda del sector vitivinícola català entre el 1892 i el 1935», Recerques, 15.

REDONET, Luis (1924): Crédito agricola: Historia, bases y organización, Madrid, Calpe.

ReINAudo, Ives (1980): «Syndicalime agricole de base», Le Mouvement Social, juillet-septembre, pp. 79-85.

Rivas, Francisco (1923): Las Cajas Rurales, Madrid, Calpe.

(1926): Los progresos del campo y la cooperación, Madrid, H. Quintana.

Robledo, Ricardo (1984): La renta de la tierra en Castilla la Vieja y León, Madrid, Banco de España.

Rogers, E. M., y Svenning, L. (1973): La modernización entre los campesinos, México, FCE.

SANCHEZ, Fernando (1979): Sindicalismo agrario y movimiento obrero, Cáceres, Caja de Ahorros.

SAPELLI, Giulio, ed. (1981): Il movimento cooperativo in Italia, Torino, Einaudi.

SERvolin, Claude (1984): «Algunas reflexiones teóricas sobre el estudio de las organizaciones profesionales agrarias», Agricultura y Sociedad, 31, pp. 17-31. 
Solberg, Carl E. (1987): The Prairies and the Pampas, Stanford University Press.

VICENT, Antonio (1906): El problema agrario resuelto por los sindicatos agricolas, Zaragoza, Centro de Publicaciones Católicas.

Villares, Ramón, y Fernandez PRIETO, Lourenzo (1992): «La crisi agrària del final del segle XIX i l'adaptació de l'explotació pagesa gallega», Recerques, 26, pp. 89-106.

YolDI, Antonino (1916): «Conferencias sobre historia del movimiento social agrario en Navarra», en Semana Social de España. Sexto curso. Pamplona, 1912, Pamplona, La Acción Social, pp. 501-561. 